\title{
Expression of Leptin In Early Placental Development- Its Association With Maternal Nutritional Status
}

\author{
Babu Geddam JJ, Radhakrishna KV, Ramalaxmi BA, Ravinder P and Balakrishna N \\ National Institute of Nutrition, Indian Council of Medical Research, Jamia Osmania (P.O), Hyderbad-500 604, India
}

\section{ABSTRACT}

Background: Placenta is a transient embryonic organ of communication between mother and fetus during pregnancy and is the only channel for transfer of nutrition as well as other factors from mother to fetus. Placental tissues from humans contain leptin and its receptors. As already known leptin is an endocrine hormone and growth factor that is important for the regulation of body fat, feeding and energy homeostasis and also plays a crucial role. Objectives: To assess and compare the expression of leptin in the products of consumption during early gestation (5 to 12 weeks) from mothers of low and high socioeconomic status groups (LSEG and HSEG) and to relate to their nutritional status. Material: Products of conception obtained at 5 to 12 weeks of gestation, from healthy women undergoing medical termination of pregnancy constituted the study material. Methodology: A total about 18 placental samples from low and 11 from high socio economic group (HSEG) were examined. Products of conception obtained from the scrapings of basal plate after vacuum extraction following termination of pregnancy were stored in formalin. Sections from basal plate were selected and stained for leptin. Imuuno histochemical stained sections were studied for percentage of villi, percentage of cytotrophoblast and percentage of stained positive blood vessels as well as intensity of staining pattern were carried out by using kits (Santa Cruz, Biotechnology, California). Nutritional status of the subjects were measured by recording weight, height, hemoglobin, serum retinol, serum folic acid and serum zinc levels. Results: Percentage of villi staining positively for leptin was significantly higher $80.7 \%(P<0.05)$ in the undernourished group when compared to well nourished $70.8 \%$ but expression of leptin in Cytotrophoblast (CTB) was significantly $59.7 \%(P<0.05)$ higher in well-nourished group. Conclusion: Expression of leptin in villi was significantly higher in the undernourished groups as compared to well nourished group.

Keywords: Leptin and maternal nutrition

\section{INTRODUCTION}

Leptin is a $16 \mathrm{Kda}$ adipocyte derived protein encoded by the $\mathrm{Ob}$ gene and is important for neuroendocrine regulation of body fat, feeding behavior, energy homeostasis, reproduction, puberty and pregnancy. ${ }^{1}$ Leptin hormone is principally synthesized in white adipose tissue, although its expression appears to be much more in the stomach, muscle, placenta and fetal tissue. ${ }^{2}$ Placenta is the source as well as target for the action of leptin. Human placental

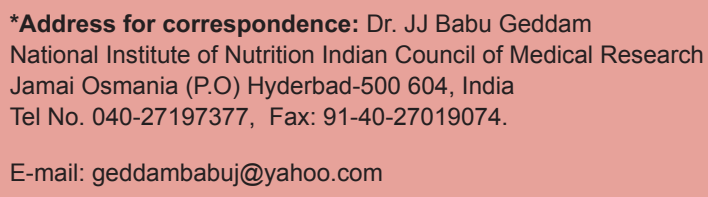

DOI: 10.5530/ijmedph.2.3.5 leptin is identical to that derived from adipose tissue in terms of size, charge and immunoreactivity., The human placenta contains substantial amounts of leptin m RNA and protein. ${ }^{4}$ The human leptin mRNA and proteins are localized to the syncitiotrophoblast at the maternal interface. ${ }^{3}$ Leptin gene is also expressed in the villous vascular endothelial cells, which are in direct contact with the fetal blood. The first trimester placental villi secrete 50 fold higher levels of leptin compared to term villi and potentiated by interleucin(IL), $1 \alpha$ oestradiol and IL- $6 .{ }^{5}$

Leptin may play a pivotal role in the trophoblast invasion of spiral arteries. The expression of leptin and leptin $\mathrm{R}$ in extravillous cytotrophoblast columns suggests that it may be involved in enhancement of the activity or in the synthesis of molecules which regulate trophoblastic invasion. ${ }^{6}$ Leptin $\mathrm{OB}-\mathrm{R}$ has been identified in the vascular endothelial cells of various fetal 
blood vessels of chorionic villi during the first trimester of pregnancy, Mulhlhauser J have shown that leptin promotes placental angiogenesis by acting synergistically with several growth factors like vascular endothelial growth factor (VEGF), basic fibroblast growth factor and platelet derived growth factor B. ${ }^{7}$ Recent literature confirms the functional role of leptin as a feto maternal placental hormone, which regulates energy balance metabolism, growth and development of normal as well as growth restricted fetuses in the intrauterine and extra uterine life. It is an important fetal growth factor and influences the fetal fat accretion. The physiological role of maternal leptin during pregnancy is enigmatic. Pregnancy is a hypermetabolic state with an increase in maternal body fat, weight and an alteration in neuro endocrine mileu. In pregnancy, there is positive energy balance with an increase in food intake aiming at preservation of maternal energy system.

\section{SUBJECTS AND METHODS}

The study was approved by the Institutional Human Ethics Committee and informed concerned was taken from the subjects. The products of conception were collected from healthy women undergoing medical termination of unwanted pregnancy in the first trimester (5-12 weeks). Women who were tested positive for VDRL, HIV, prolonged hyperemesis, history of bacterial infections and history of congenital malformations were excluded from the study. A total 39 samples of products of conception were collected between 5-12 weeks of gestation assessed by the date of last menstrual period. Of the 39 samples, 18 were obtained from a Government Hospital (Niloufer Hospital, Hyderabad), which caters to the low socioeconomic group and 11 from a private nursing home, that caters to the high socioeconomic group.

Products of conception were immediately fixed in 10\% buffered neutral formalin. The entire material was sampled, processed and $3 \mu \mathrm{g}$ paraffin sections were cut to obtain $3 \mu \mathrm{g}$ serial sections. Sections were stained haemotoxylin and eosin. Every fifth section was taken for the study. Slides were examined by light microscopy and those slides showing good number of villi and implantation sites with anchoring villi were selected for immunohistochemistry. The leptin expression was seen in villi (Fig. 1), expression in the Cytotrophoblast (Fig. 2) and also in the blood vessels staining intensity pattern was seen in the both groups.

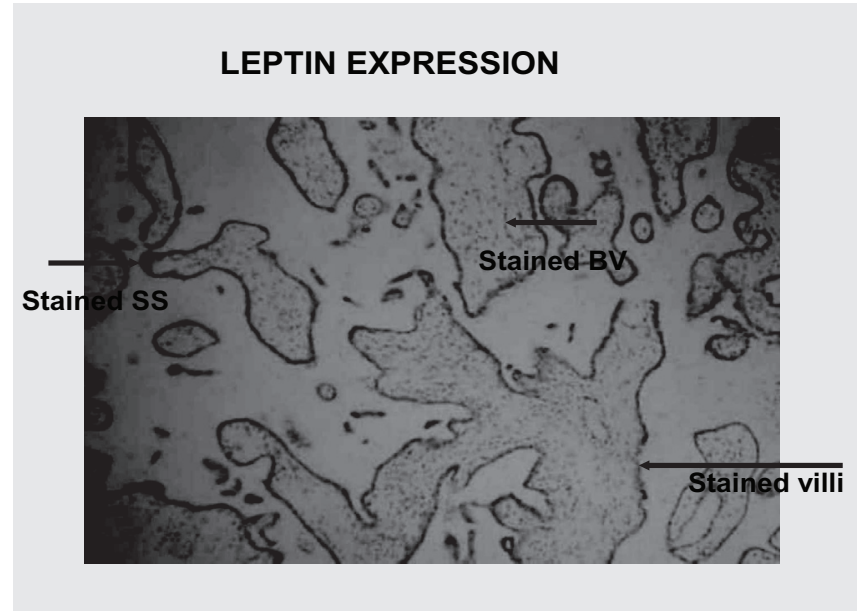

Figure 1. The leptin expression was seen in villi.

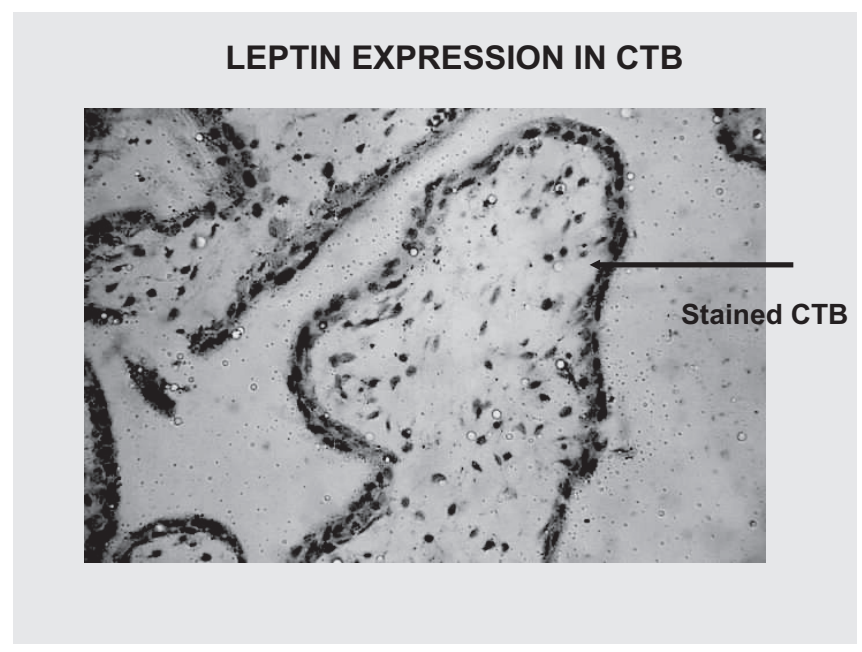

Figure 2. Expression in the Cytotrophoblast.

\section{LEPTIN IMMUNOHISTOCHEMISTRY}

Leptin staining was done by using Santa cruz kits (USA) except the primary antibody for leptin which was obtained from National Hormone and Pituitary Programme, National Institute of Health, USA. After selecting the slide having implantation site the immunohistochemistry studies were carried out for leptin expression. Briefly the staining procedures involved deparaffinization, hydration by using xylene and alcohol and distilled water. Sections were transferred to $0.1-\mathrm{M}$ citrate buffer and autoclaved at $120^{\circ} \mathrm{C}$ for 5 minutes for antigen retrieval. Slides were cooled in buffer for 20 to 30 minutes and washed in $1.1 \mathrm{~m}$ PBS. Excessive PBS was drained off and endogenous peroxidase activity was blocked for 30 minutes. Sections were again drained and washed with PBS. Sections were layered with blocking antibody goat serum for 15 minutes and excessive serum was blotted. Then sections were 
layered with leptin antibody was then applied (NHPP, NIH, USA) incubated for 2 hours at room temperature, slides were washed in PBS drained again and wiped.

Biotinyated $2^{\text {nd }}$ antibody was then applied for 30 minutes and washed with PBS again. Slides were drained and wiped followed by Avidin biotin peroxidase reagent for 30 minutes and washed with PBS. The DAB solution was applied for 7 minutes and the slides were rinsed in distilled water for 5 minutes. Sections were counterstained with Meyer's hematoxylin for 5 minutes and rinsed in the distilled water for 6 minutes. Dehydration was accomplished by dipping the slides in $50 \%, 70 \%$, and 95\% absolute alcohol for five minutes each. Slides were again dipped in 1:1 xylene and alcohol and xylene for five minutes each and were mounted with DPX positive and negative control.

SCORING METHOD: After Immunohistochemistry staining, four peripheral and one central fields of each slide were scored to cover 100 villi from each sample.

BIOCHEMICAL PARAMETERS: $5 \mathrm{ml}$ of venous blood was collected from each subject before they underwent medical termination of pregnancy. Hemoglobin (cynomethemoglobin method), serums zinc (atomic absorption spectrophotometry) method, folic acid (radioimmunoassay) and Vit A (HPLC) were determined.

ANTHROPOMETRIC MEASUREMENTS: Anthropometric measures such as height and weight were determined in the subjects using standard methods and equipment ${ }^{8}$ (Jellife, $\mathrm{DB}, 1966)$. Body mass index (BMI) was also calculated for determining the nutritional status of each subject.

STATISTICAL METHODS: SPSS windows version 11.5 was used for data analysis. Student' $t$ ' test was applied to compare the mean values of maternal characters and leptin expression of different socioeconomic groups. Confidence intervals were also calculated for each parameter. Statistical significance was considered at a $\mathrm{P}$ value $<0.05$.

\section{RESULTS}

Woman belonging to undernourished and well-nourished were comparable in age (Table 1). Woman of LSEG had significantly $(\mathrm{P}<0.01)$ lower mean body weight
Table 1: Baseline characters of the subjects

\begin{tabular}{|c|c|c|}
\hline VARIABLES & LSEG $(n=18)$ & HSEG $(n=11)$ \\
\hline Age (yrs) & $26.94(5.29)$ & $28.91(5.78)$ \\
\hline Para & $1.89(1.28)$ & $1.38(0.744)$ \\
\hline Weight ** (kg) & $48.16(12.54)$ & $62.18(9.51)$ \\
\hline Height (cm) & $153.1(5.73)$ & $156.41(9.36)$ \\
\hline $\mathrm{BMI}^{\star *}$ & $20.48(4.96)$ & $26.29(1.75)$ \\
\hline $\mathrm{Hb}(\mathrm{g} / \mathrm{dl})$ & $9.81(1.21)$ & $10.22(0.57)$ \\
\hline Serum retinol $^{*}(\mu \mathrm{g} / \mathrm{dl})$ & $29.12(10.49)$ & $21.71(4.86)$ \\
\hline Serum folic acid $(\mu \mathrm{g} / \mathrm{dl})$ & $6.41(3.18)$ & $8.27(4.75)$ \\
\hline Serum zinc $(\mu \mathrm{g} / \mathrm{dl})$ & $107.12(28.59)$ & 98.96 (33.33) \\
\hline
\end{tabular}

in comparison with the high socioeconomic group. Women of high socioeconomic group had a significantly $(\mathrm{P}<0.01)$ more BMI in comparison to low socioeconomic group. Micronutrients like serum folic acid and serum zinc was within normal range and comparable. The Hemoglobin levels of both groups were in normal range and comparable.

Percentage of villi stained for leptin was significantly higher $(\mathrm{P}<0.05)$ in the undernourished group than the well-nourished group. But expression of leptin in cytotrophoblst was more in the well-nourished group (Table 2), whereas expression of leptin in vessels was comparable in two groups.

\section{DISCUSSION}

The results show gross differences between the two groups in anthropometric data and serum retinal levels which might reflect the overall chronic nutrient deficiency in both micro and macronutrient status show significant differences among the two groups.

Increased food intake, decreased insulin sensitivity and hyperlipedemia are major features during pregnancy. ${ }^{9}$ These changes are beneficial in providing energy to the fetus and preparing the mother for

\begin{tabular}{|c|c|c|}
\hline Leptin & LSEG $(n=18)$ & HSEG $(n=11)$ \\
\hline$\%$ of Villi with positive staining & $80.71^{*} \pm 1.89$ & $70.76 \pm 3.65$ \\
\hline$\%$ of CTB positive staining & $59.73^{*} \pm 1.77$ & $64.96 \pm 0.93$ \\
\hline$\%$ of stained blood vessels & $6.611 \pm 0.48$ & $7.64 \pm 0.84$ \\
\hline \multirow[t]{3}{*}{ Intensity of staining } & $16.7 \%(3)$ & $27.3 \%(3)$ \\
\hline & $27.81 \%(5)$ & $54.5 \%(5)$ \\
\hline & $55.6 \%(10)$ & $18.2 \%(2)$ \\
\hline
\end{tabular}

Values are mean and SD *P $<0.05 ; * * \mathrm{P}<0.01$

LSEG = LOW SOCIO ECNOMIC GROUP

HSEG = HIGH SOCIOECNOMIC GROUP 
nursing. During pregnancy, the placenta becomes an important additional source of leptin, which is primarily secreted into maternal circulation. ${ }^{10,11}$ The presence of leptin and all leptin receptors in placenta from very early stages of development until term suggests that placental leptin acts locally and also had a various biological effects. Leptin stimulation of metalloproteinases like MMP9 in early cytotrophoblast cells provides a potential function for leptin and its receptor in placental invasion. ${ }^{12}$

The present study shows percentage of villi stained for leptin was significantly $(\mathrm{P}<0.05)$ higher in the LSEG groups but expression of leptin in cytotrophoblast was higher in the HSEG. It indirectly indicates placental invasion was more in the HSEG because of increased expression of leptin in the cytotrophoblast and cytotrophoblast occupies a crucial role in implantation.

Further studies are needed with a bigger sample size at different gestational ages in early pregnancy, to determine the exact nature of leptin, which affects the development of placenta and implantation.

\section{AUTHORS' CONTRIBUTION}

Dr. J. J. Babu Geddam: Conducted the IHC, morphometry, data analysis and interpretation of results and writing of manuscript. Dr. Radhakrishna KV: Contribution of data analysis and interpretation of results. Dr. Ramalakshmi BA: Recruitment of subjects and gynaecological examination of subjects and collection of the placental samples. Dr. P Ravinder: Cross checking of IHC slides and quality control of staining. Dr. Balakrishna: Statistical analysis and interpretation of data.

\section{ACKNOWLEDGMENTS}

We are thankful to Dr. B. Sesikiran, Director and Dr. P. Bhaskaram, Former Deputy Director (Sr. Gr.), National Institute of Nutrition, Hyderabad for their contribution to this project. We thank the staff of Niloufer Hospital for Women and Children, Hyderabad and Dr. Savita Devi, Chief Obstetrician and Gynecologist of Swapna Nursing Home, Hyderabad, India, for their assistance in this study. The technical assistance of Mr. B. N. Goud, Mrs. Sharada, Mr. Ch. Hanumantha Reddy and Mr. A. Kiran Kumar are highly acknowledged.

\section{REFERENCES}

1. Bajoria R, Sooranna SR, Ward BS, et al. Prospective functions of placental leptin at maternal-fetal interface, Placenta, 2002-a Review 23:103-15.

2. Harris, R S B. Ann.Review of Nutrition, 2000; 20: 45-75.

3. Hassink SG, de Lancey E, Sheslow DV, et al. Placental Leptin: An important new growth factor in intrauterine and neonatal development. Pediatrics, 1997; 100 (1):1-6.

4. Masuzaki H, Ogwa $\mathrm{Y}$, Sagwaw N, et al. Non adipose tissue production of leptin : Leptin as novel placental derived hormone in human. Nat medicine, 1997; 3:1029-33.

5. Meisser A, Cameo P, Islami D, et al. Effects of Interleucin (IL)-6 (IL-6) on cytotrophoblastic cells. Mol Hum Reproduction, 1999; 5:1055-8.

6. Kaufmanon Castellucce M. Extra villous trophoblast in the human. Placental Trophoblast Res. 1997; 10:21-65.

7. Muhlhauser J, Marziond, Morone M, et al. Co-distribution of basic fibroblast growth factor and heparin sulfate proteoglcan in the growth zones of human placenta. Cell Tissue Research,1996; 285:101-7.

8. Jellife, DB. 1966: Assessment of nutritional status of communities. WHO

9. Abrams B and Pickch KE (1999). Maternal nutrition. In maternalfetal medicine, 4th edn (Ed) Creasy RK and Rasini KR, PP-122-131. Phildelphia, Pensylvania, W.B saunders company.

10. Linnerman $\mathrm{K}$ and malek $\mathrm{A}$, Sager et al. Leptin production and releases in the dually in vitro perfused human placenta. J. Clin. Endocrinol meta, 2000; 85:4298-301.

11. Lipercq J, Challier JC, Guerremillon M, et al. Prenatal leptin production: Evidence that fetal adipose tissue produces leptin. J. Clin Endocrinol Metab, 2001; 86:2409-13.

12. Cestellucci M and Dematteis R, Meisser A, Cancello R, Mansurro V, Islami D Leptin modulates extra cellular matrix molecules and metalloproteinases: Possible implications for trophoblast invasion. Mol Hum. Reproud, 2000; 6:951-8. 